Part of Journal of Research of the National Bureau of Standards, Volume 27, December 1941

\title{
FREE ENERGIES AND EQUILIBRIA OF ISOMERIZATION OF THE BUTANES, PENTANES, HEXANES, AND HEPTANES 1
}

\author{
By Frederick D. Rossini, Edward J. R. Prosen, and Kenneth S. Pitzer ${ }^{2}$
}

\section{ABSTRACT}

There are presented in tabular and graphical form, for the two butanes, the three pentanes, the five hexanes, and the nine heptanes, all in the ideal gaseous state, for the range $298^{\circ}$ to $1,000^{\circ} \mathrm{K}$, values of the following thermodynamic properties: (a) the standard free energy of isomerization divided by the absolute temperature, $\Delta F^{\circ} / T$; and (b) the relative amounts of the several isomers present when at equilibrium with each other. Comparison is made of these calculated values of the equilibrium concentrations with the directly measured values reported by other investigators for equilibria involving (a) the two butanes, (b) two pentanes, and (c) four hexanes.

\section{CONTENTS}

I. Introduction

II. Results in tabular and graphical form

III. Comparison with direct measurements of equilibria

IV. Conclusion .

V. References

541

\section{INTRODUCTION}

In this paper there are reported values of the standard free energies of isomerization, and the corresponding equilibrium concentrations, for the two butanes, the three pentanes, the five hexanes, and the nine heptanes, all in the ideal gaseous state, for the range $298^{\circ}$ to $1,000^{\circ} \mathrm{K}$. These values have been calculated in the following way:

There are given in papers already published, values of the heat of isomerization at $0^{\circ} \mathrm{K}, \Delta H_{0}^{\circ}$, for the normal paraffin to the branchedchain isomer $[10,11,9]$, and values of the free-energy function, $\left(F^{\circ}-H_{0}^{\circ}\right) / T$, for each isomer $[8]^{3}{ }^{3}$ For the isomerization of the normal paraffin to the isoparaffin (normal and iso being indicated by the italic letters $n$ and $i$, respectively),

$$
n-C_{a} H_{b} \text { (gas) }=i-C_{a} H_{b} \text { (gas), }
$$

$\Delta F^{\circ}$ is the standard free-energy change at a given temperature, with each component in its ideal standard state of unit fugacity, and

$$
\Delta\left(\frac{F^{\circ}-H_{0}^{\circ}}{T}\right)=\left(\frac{F^{\circ}-H_{0}^{\circ}}{T}\right)_{i}-\left(\frac{F^{\circ}-H_{0}^{\circ}}{T}\right)_{n} .
$$

1 Presented before the Division of Petroleum Chemistry of the American Chemical Society at Atlantic City, N. J., September 11, 1941.

2 Professor of Chemistry, University of California, Berkeley, Calif.

3 Figures in brackets indicate the literature references at the end of this paper. 
But

and

$$
\Delta\left(\frac{F^{\circ}-H_{0}^{\circ}}{T}\right)=\frac{\Delta F^{\circ}}{T}-\frac{\Delta H_{0}^{\circ}}{T}
$$

$$
\frac{\Delta F^{\circ}}{T}=-R \ln K,
$$

where $K$ is the equilibrium constant, as defined by Lewis and Randall [4]. Then

$$
\frac{\Delta F^{\circ}}{T}=-R \ln K=\frac{\Delta H_{0}^{\circ}}{T}+\Delta\left(\frac{F^{\circ}-H_{0}^{\circ}}{T}\right) .
$$

For the isomerization reaction as given by eq 1 ,

and, for low pressures,

$$
K=f_{i} / f_{n},
$$

$$
K=p_{i} / p_{n},
$$

where $f$ represents the fugacity (see [4]) and $p$ the partial pressure.

\section{RESULTS IN TABULAR AND GRAPHICAL FORM}

The thermodynamic quantities calculated in this way from the data referred to are given in table 1. The first two columns give the temperature in centigrade and Kelvin degrees, respectively, with the former rounded off in reference to the latter, the difference being not at all significant here. The succeeding columns give for each isomer of the butanes, pentanes, hexanes, and heptanes, respectively, values of the following thermodynamic properties: $\Delta F^{\circ} / T$, which is the standard free-energy change divided by the absolute temperature, for the reaction of isomerization in the gas phase, as expressed by eq 1; $K$, which is the equilibrium constant, defined by eq 4 and 6 , for the reaction expressed by eq 1 ; and $\mathrm{N}$, which is the mole fraction of the given isomer present when at equilibrium with all of its other isomers. Strictly, the value of $\mathrm{N}$ so calculated is applicable only in the range from zero pressure up to that pressure at which the ratio of fugacity to pressure is still not significantly different for the several isomers. Within this range of pressure, the value of $K$ in table 1 gives directly the ratio of the amount of the given isomer to the amount of the normal isomer in equilibrium with it in the gas phase. For any two other isomers, the ratio of the corresponding values of $K$ in table 1 gives the ratio of the amounts of those two isomers present when at equilibrium in the gas phase with one another.

The limits of uncertainty of the values of $\Delta F^{\circ} / T$ given in table 1 are estimated to be as follows, for the range $298^{\circ}$ to $1,000^{\circ} \mathrm{K}$ : For the butanes, $\pm 0.75 \mathrm{cal} / \mathrm{deg}$ mole; for the pentanes, $\pm 1.0 \mathrm{cal} / \mathrm{deg} \mathrm{mole}$; for the hexanes, $\pm 1.0 \mathrm{cal} / \mathrm{deg}$ mole; and for the heptanes, $\pm 1.3 \mathrm{cal} / \mathrm{deg}$ mole. This same uncertainty applies to the value of $\Delta \bar{F}^{\circ} / T$ for the isomerization of any one of the isomers into any other one. From these values, one may easily derive the corresponding uncertainties in the values of the equilibrium constants and the equilibrium concentrations, as illustrated in figures 9 and 11. For the purpose of retaining the significance of their change with temperature, the values in table 1 are written with more figures than the foregoing uncertainties would normally warrant. 


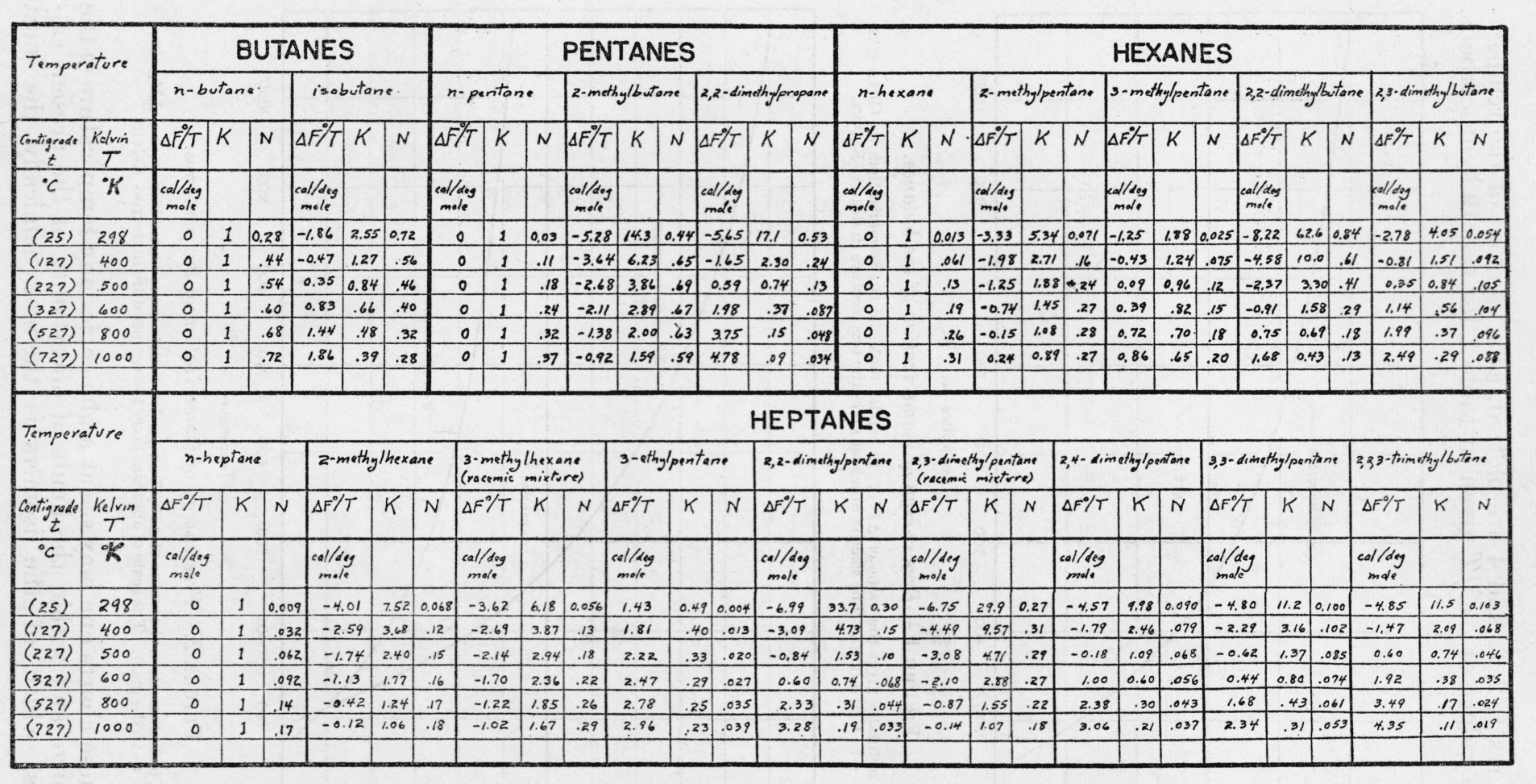

TABLE 1.- Summary of values of the free energies, equilibrium constants, and equilibrium concentrations, for the isomerization of the butanes, pentanes, hexanes, and heptanes, in the ideal gaseous state, from $298^{\circ}$ to $1,000^{\circ} \mathrm{K} .{ }^{*}$

- The estimated uncertainties, expressed for $\Delta F^{\circ} / T$, from $298^{\circ}$ to $1,000^{\circ} \mathrm{K}$, are as follows, in cal/deg mole: butanes, \pm 0.75 ; pentanes, \pm 1.00 ; hexanes, \pm 1.00 ; heptanes, \pm 1.30 . 
In figures $1,2,3$, and 4 are plotted, as a function of the temperature, the values of $\Delta F^{\circ} / T$ given in table 1 for the 19 hydrocarbons.

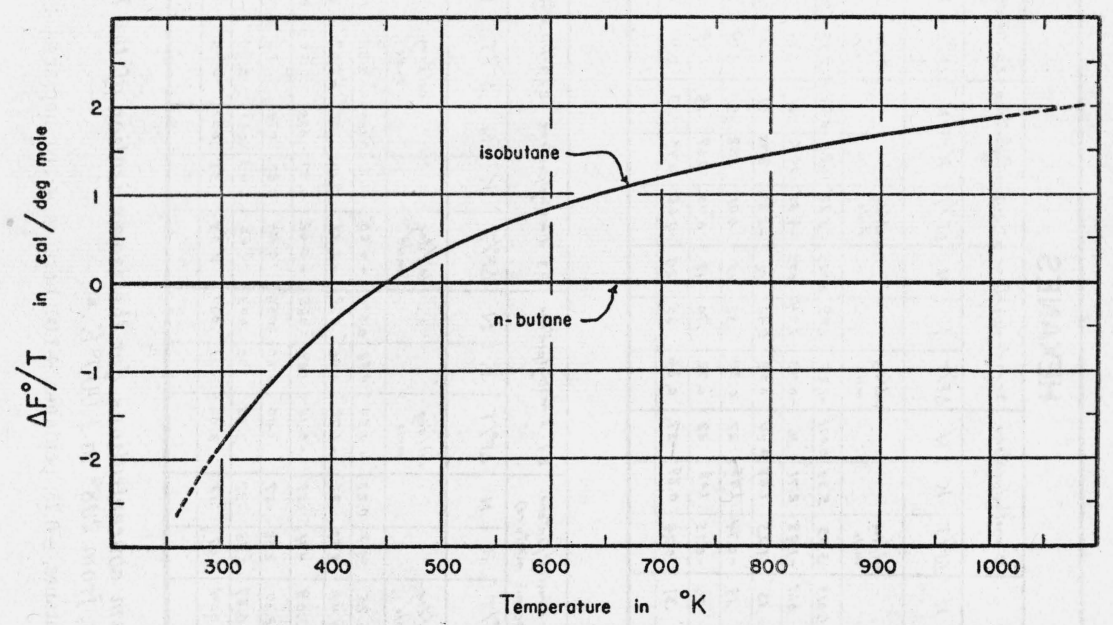

FIGURE 1.-Free energy of isomeization of the butanes.

The scale of ordinates gives the value of $\Delta F^{\circ} / T$, in cal/deg mole, for the isomerization, $n-\mathrm{C}_{4} \mathrm{H}_{10}$ (gas) $=i-\mathrm{C}_{4} \mathrm{H}_{10}$ (gas). The scale of abscissas gives the temperature in degrees Kelvin.

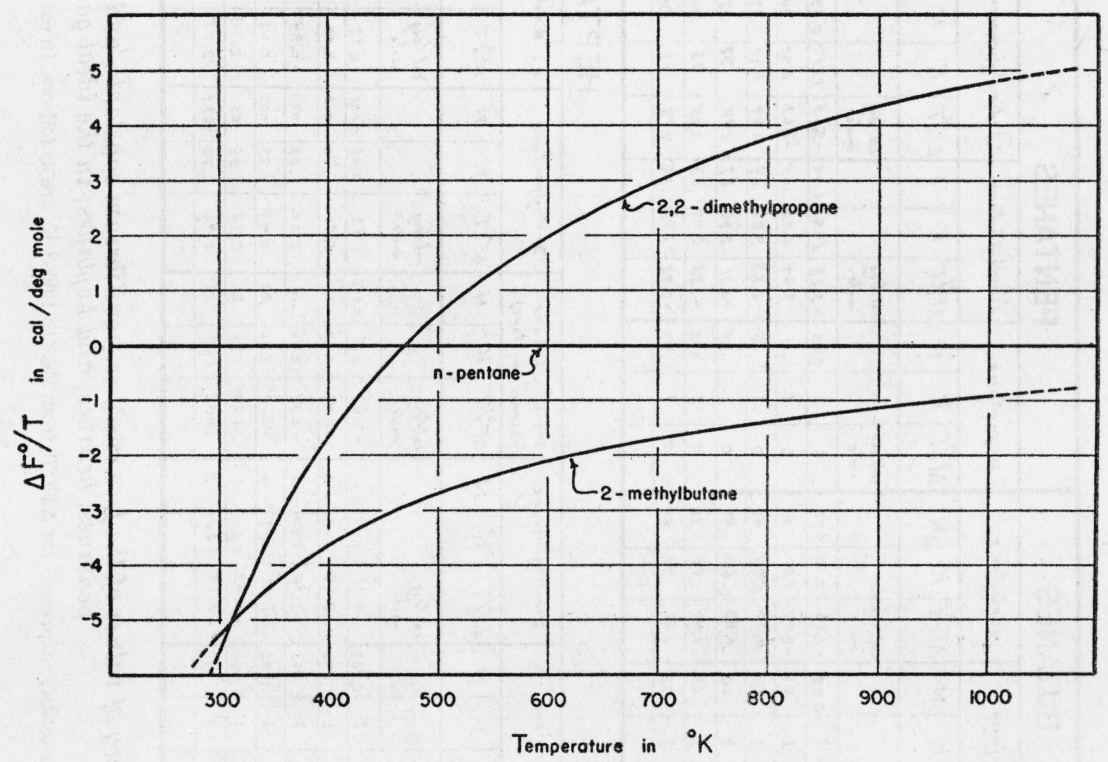

Figure 2.-Free energy of isomerization of the pentanes.

The scale of ordinates gives the value of $\Delta F^{\circ} / T$, in cal/deg mole, for the isomerization, $n-\mathrm{C}_{8} \mathrm{H}_{12}$ (gas)= $i-\mathrm{C}_{5} \mathrm{H}_{12}$ (gas). The scale of abscissas gives the temperature in degrees Kelvin.

From these charts one may see at a glance, for any temperature in the given range and within the limits of uncertainty of the present calculations, which of the isomers is thermodynamically the most 
stable (lowest value of $\Delta F^{\circ} / T$ ), which is the least stable (highest value of $\Delta F^{\circ} / T$ ), and the order of stability of the other isomers. From the preceding discussion regarding uncertainties, it follows that those isomers having at some given temperature values of $\Delta F^{\circ} / T$ that differ by less than the uncertainty are ones for which the exact order of stability cannot be stated, since the values overlap. In such cases, the amounts present at equilibrium will be equal within the given limits.

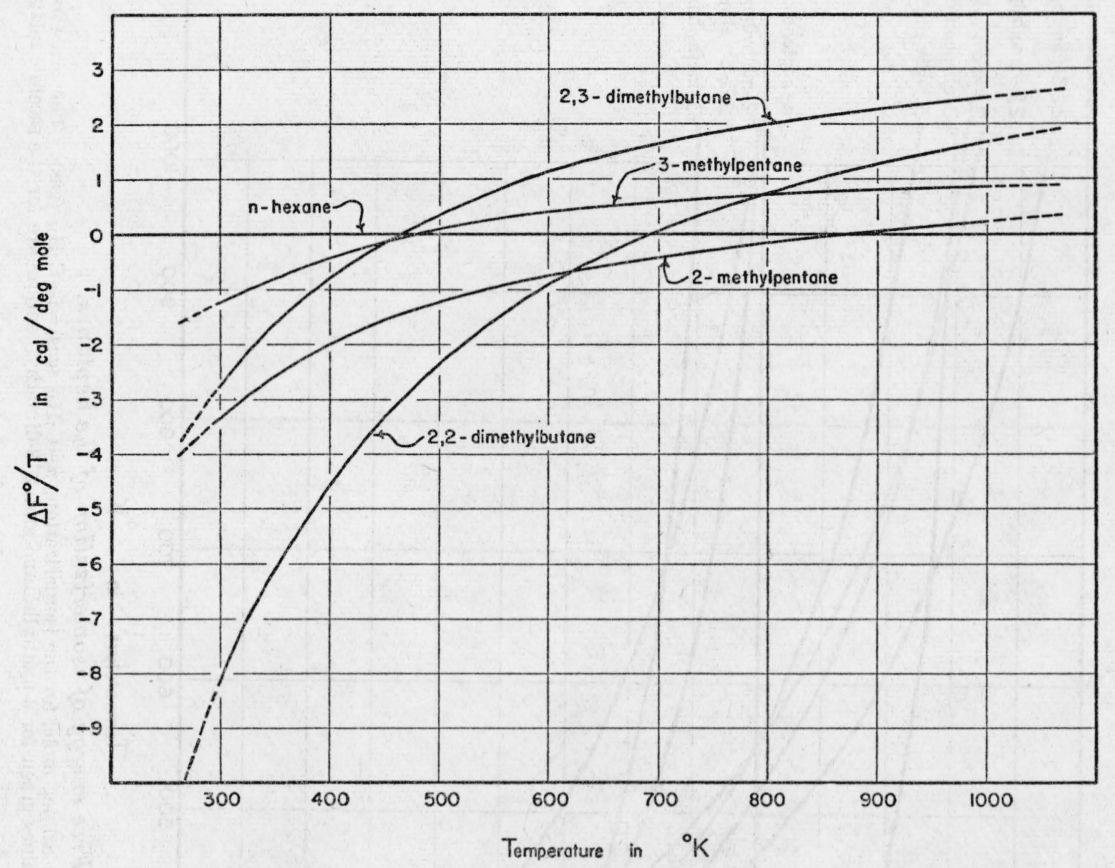

FigURe 3.-Free energy of isomerization of the hexanes.

The scale of ordinates gives the value of $\Delta F^{\circ} / T$, in cal/deg mole, for the isomerization, $n-\mathrm{C}_{6} \mathrm{H}_{14}$ (gas) $=i-\mathrm{C}_{6} \mathrm{H}_{14}$ (gas). The scale of abscissas gives the temperature in degrees Kelvin.

In figures $5,6,7$, and 8 are plotted, as a function of the temperature, for the butanes, pentanes, hexanes, and heptanes, respectively, the amounts, in mole fraction, of each of the isomers present when at equilibrium with all its other isomers in the gas phase, as given in table 1. The vertical width of each band gives the mole fraction for that isomer at the selected temperature. The mole fractions of the several isomers are plotted additively, so that their sum is unity at all temperatures. For example, figure 8 shows how, within the limits of uncertainty previously given, 1 mole of $\mathrm{C}_{7} \mathrm{H}_{16}$ molecules distribute themselves among the nine isomeric forms of heptane at thermodynamic equilibrium in the gas phase from $260^{\circ}$ to $1060^{\circ} \mathrm{K}$, for those pressures where the ratio of fugacity to pressure is substantially the same for the given isomers. 


\section{COMPARISON WITH DIRECT MEASUREMENTS OF EQUILIBRIA}

In figure 9 are compared the available data on the direct determination of the concentrations of $n$-butane and isobutane present

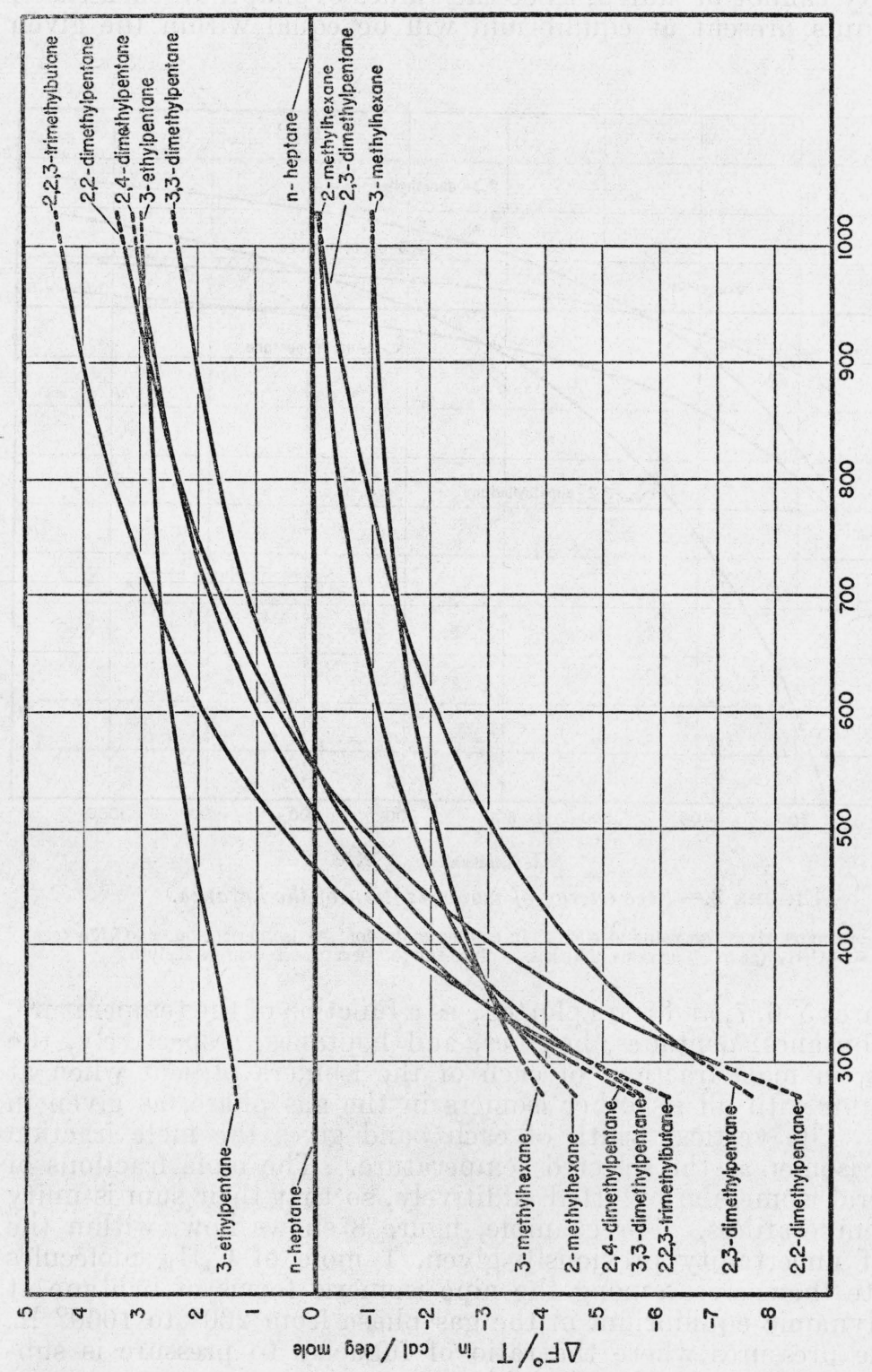

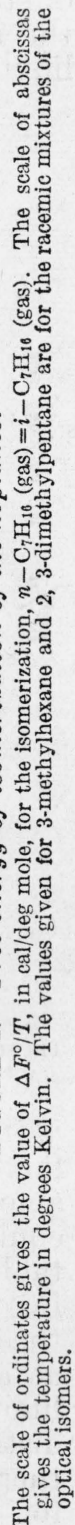

when at equilibrium with one another, as reported by De Simo, McMillan, and Cheney [3], Moldarskii and Nizovkina [5], Montgomery, McAteer, Franke, and Horne [6, 7], and Schuit, Hoog, and Verheus [13], with the values for the same quantities as derived 
from table 1. In those several cases where the direct determination of the equilibrium concentrations was made for the liquid phase,

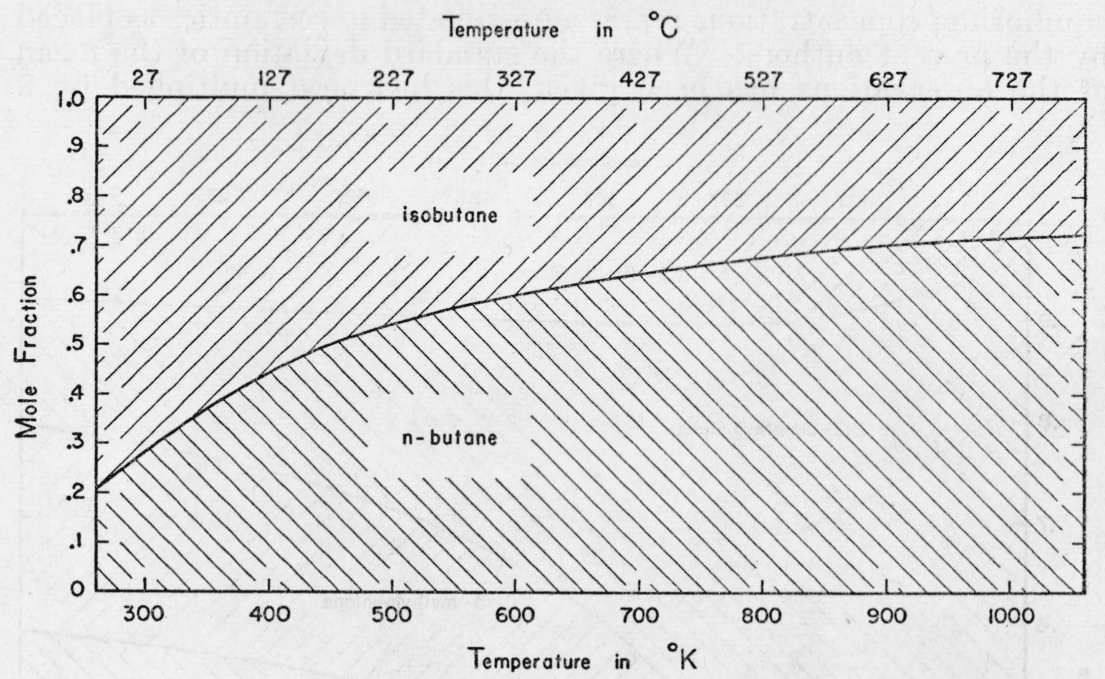

Figure 5.-Equilibrium concentrations of the butanes.

The scale of ordinates measures the amount in mole fraction, and the scale of abscissas gives the tempera. ture in degrees Kelvin and degrees centigrade. The vertical width of a band at a given temperature measures the mole fraction of the given isomer present when at equilibrium with all of its other isomers, in the gas phase.

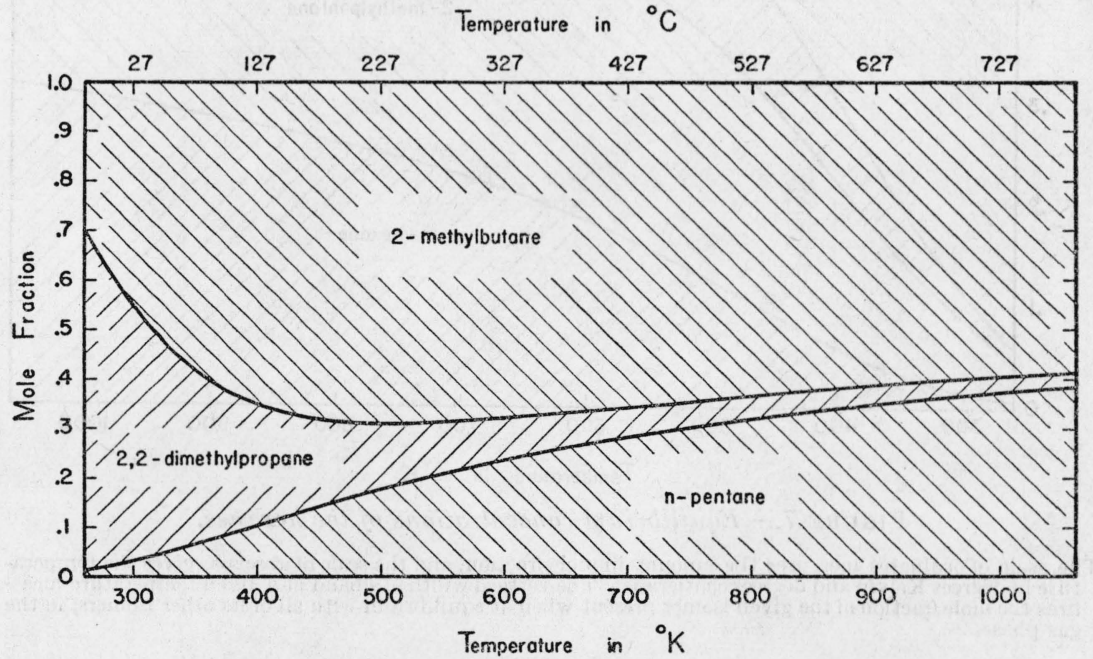

Figure 6.-Equilibrium concentrations of the pentanes.

The scale of ordinates measures the amount in mole fraction, and the scale of abscissas gives the temperature in degrees Kelvin and degrees centigrade. The vertical width of a band at a given temperature measures the mole fraction of the given isomer present when at equilibrium with all of its other isomers, in the gas phase.

the observed values were corrected to the gas phase. The solid line in figure 9 represents the amount of $n$-butane in an equilibrium mixture of the two butanes, as derived from the values in table 1. The 
broken lines parallel to the solid line indicate the estimated uncertainty in the values derived from table 1 . Likewise, the vertical arrows placed on the values of the direct determinations of the equilibrium concentrations represent estimated uncertainties as placed by the present authors. Where the standard deviation of the mean of the observations has been given, this has been multiplied by 2

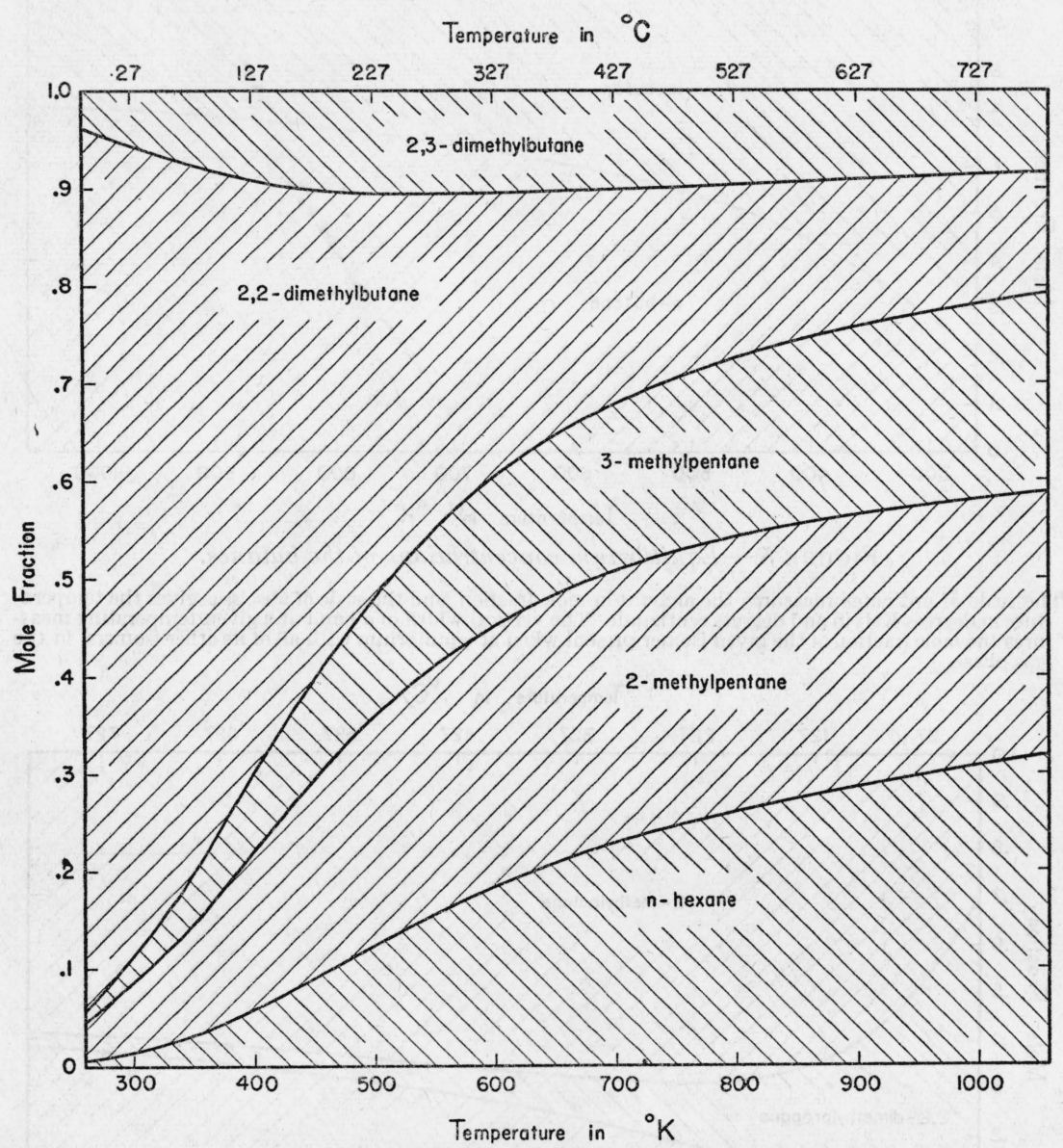

FIGURE 7.-Equilibrium concentrations of the hexanes.

The scale of ordinates measures the amount in mole fraction, and the scale of abscissas gives the temperature in degrees Kelvin and degrees centigrade. The vertical width of a band at a given temperature measures the mole fraction of the given isomer present when at equilibrium with all of its other isomers, in the gas phase.

to yield the estimated uncertainty [12]. It may be seen from figure 9 that the direct determinations of the equilibrium concentrations are almost, but not quite, in accord with the values derived from table 1, within the respective limits of uncertainty.

The values of free energy and equilibrium concentrations given in table 1 are uniformly (see introduction) based upon (I) a combination of (a) values of heats of isomerization determined calorimetrically with (b) values of the free-energy function determined from statistical 
calculations and "third-law" entropies. A second set of values may be calculated (II) from a combination of (a) values of the equilibrium concentrations determined experimentally at or near a given selected

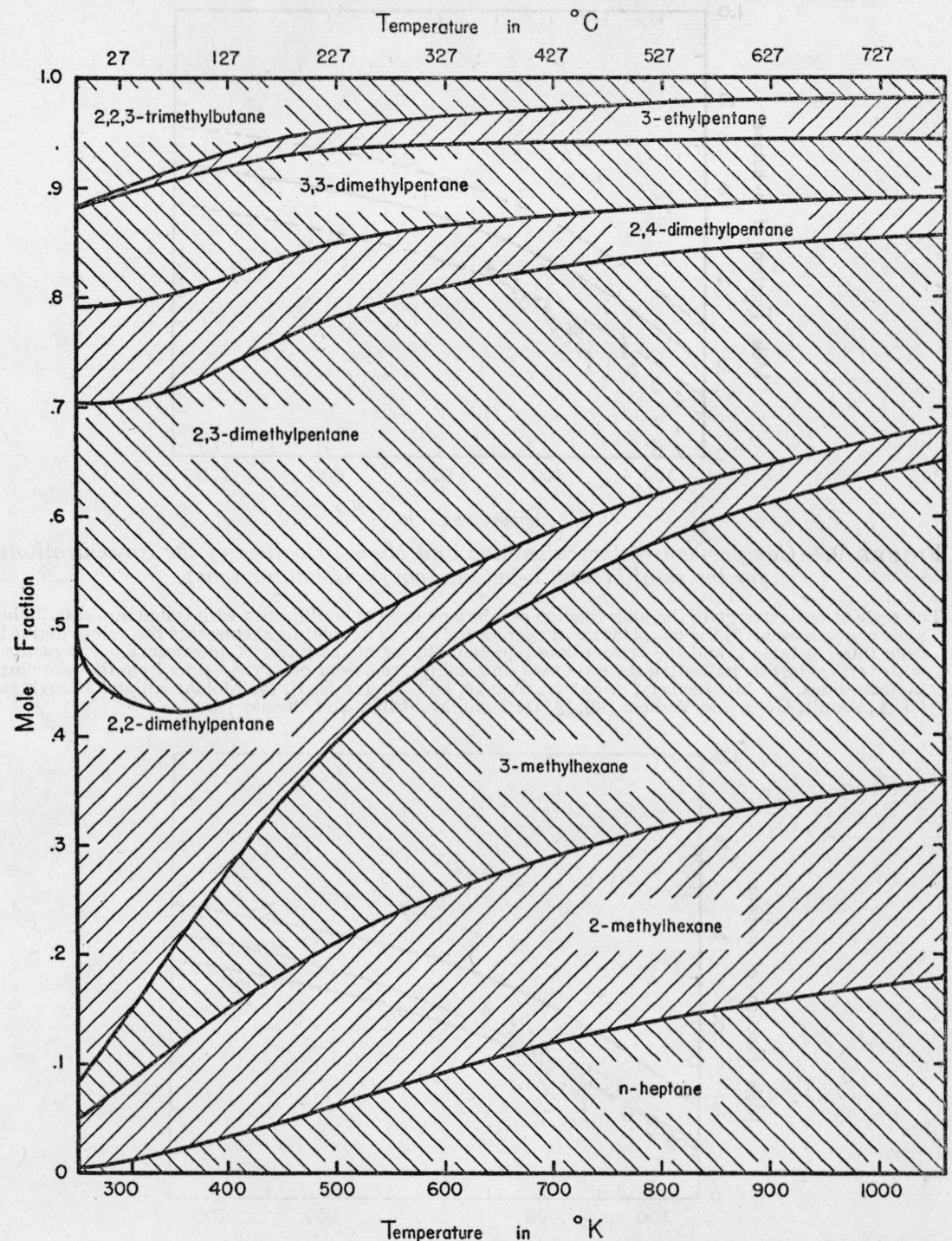

Figure 8.-Equilibrium concentrations of the heptanes.

The scale of ordinates measures the amount in mole fraction, and the scale of abscissas gives the temperature in degrees Kelvin and degrees centigrade. The vertical width of a band at a given temperature measures the mole fraction of the given isomer present when at equilibrium with all of its other isomers, in the gas phase. The values for 3-methylhexane and 2, 3-dimethylpentane are for the racemic mixture of the optical isomers.

temperature with (b) values of the free-energy function determined from statistical calculations and "third-law" entropies. A third set of values may be calculated (III) from a combination of (a) values of heats of isomerization determined calorimetrically with (b) values of 
the equilibrium concentrations determined experimentally at or near a given temperature, together with values of the heat content as a function of the temperature.

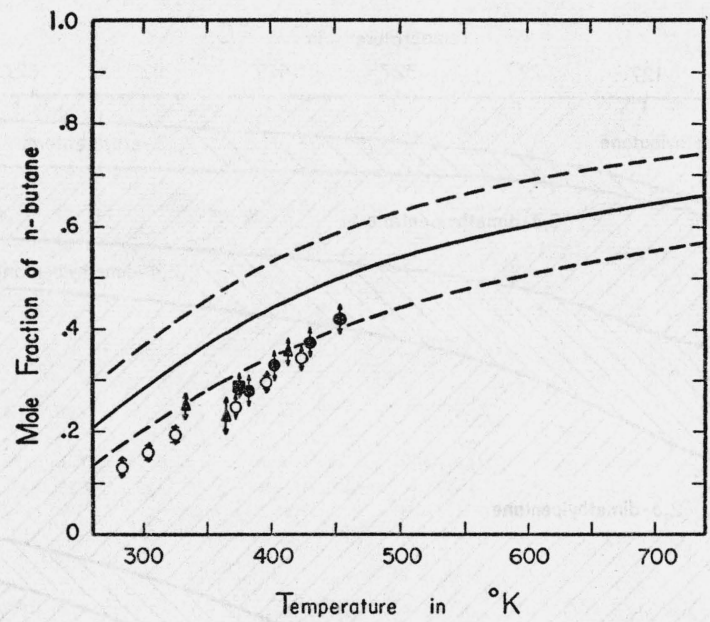

FIGURE 9.-Comparison of the calculated and observed values of the concentrations for the equilibrium, $n$-butane (gas)=isobutane (gas).

The scale of ordinates gives the mole fraction of $n$-butane (gas) at equilibrium with isobutane (gas). The scale of abscissas gives the temperature in degrees Kelvin. The solid line represents the values derived from those in table 1, and the broken lines represent the estimated limits of uncertainty. The points, with vertical arrows indicating the estimated uncertainty, represent observed values from the following investigations: O, Montgomery, McAteer, Franke, and Thorne [6, 7]; - Moldavskii and Nizovkina [5]; $\mathbf{A}$, Schuit, Hoog, and Verheus [13];

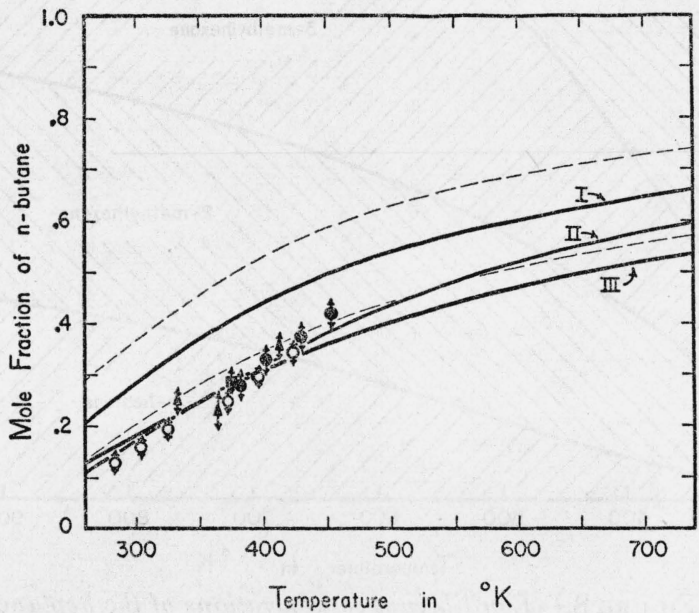

FIGURE 10.-Graphical comparsion of the three sets of values for the isomerization of the butanes.

The scale of ordinates gives the mole fraction of $n$-butane (gas) at equilibrium with isobutane (gas.) The scale of abscissas gives the temperature in degrees Kelvin. See text and table 2 for explanation.

Only for the butanes are sufficiently precise data from all three sources available, and in table 2 are presented the three sets of values so calculated for the butanes. Figure 10 shows the three sets of 
values of the equilibrium concentrations, together with the experimentally determined values as given in figure 9 . As in figure 9 , the dashed lines in figure 10 represent the limits of uncertainty of the values represented by curve I. The experimentally observed values of the equilibrium concentrations are obviously in best accord with curves II and III, since they were used to establish the location of these curves. The three sets of values are almost, but not quite, in accord within their respective limits of uncertainty. New and more accurate determinations of the heat of isomerization, or of the entropy of isomerization, or of the actual equilibrium concentrations, will make possible the selection of a final "best" set of values for the isomerization of the butanes.

TABLE 2.-Comparison of three sets of values for the isomerization of n-butane into isobutane: $n-\mathrm{C}_{4} \mathrm{H}_{10}$ (gas) $=i-\mathrm{C}_{4} \mathrm{H}_{10}$ (gas)

[See text and figure 10 for explanation.]

\begin{tabular}{|c|c|c|c|c|c|c|c|c|c|c|}
\hline \multirow{2}{*}{\multicolumn{2}{|c|}{ Temperature }} & \multicolumn{3}{|c|}{ I } & \multicolumn{3}{|c|}{ II } & \multicolumn{3}{|c|}{ III } \\
\hline & & $\Delta F^{\circ} / T$ & K & $\mathrm{N}$ & $\Delta F^{\circ} / T$ & K & $\mathbf{N}$ & $\Delta F^{\circ} / T$ & $K$ & $\mathbf{N}$ \\
\hline $\begin{array}{l}{ }^{\circ} C \\
25 \\
127 \\
227 \\
327 \\
527 \\
727\end{array}$ & $\begin{array}{l}{ }^{\circ} K \\
298 \\
400 \\
500 \\
600 \\
800 \\
1,000\end{array}$ & $\begin{array}{r}\text { cal/deg mole } \\
-1.86 \\
-0.47 \\
.35 \\
.83 \\
1.44 \\
1.86\end{array}$ & $\begin{array}{l}2.55 \\
1.27 \\
0.84 \\
.66 \\
.48 \\
.39\end{array}$ & $\begin{array}{l}0.72 \\
.56 \\
.46 \\
.40 \\
.32 \\
.28\end{array}$ & $\begin{array}{r}\text { cal/deg mole } \\
-3.20 \\
-1.47 \\
-0.45 \\
.17 \\
.94 \\
1.46\end{array}$ & $\begin{array}{l}5.0 \\
2.10 \\
1.25 \\
0.92 \\
.62 \\
.48\end{array}$ & $\begin{array}{l}0.83 \\
.68 \\
.56 \\
.48 \\
.38 \\
.32\end{array}$ & $\begin{array}{r}\text { cal/deg mole } \\
-3.00 \\
-1.60 \\
-0.79 \\
-.25 \\
.43 \\
.83\end{array}$ & $\begin{array}{l}4.5 \\
2.25 \\
1.49 \\
1.13 \\
0.80 \\
.66\end{array}$ & $\begin{array}{l}0.82 \\
.69 \\
.60 \\
.53 \\
.44 \\
.40\end{array}$ \\
\hline
\end{tabular}

In figure 11 are compared the available data on the direct determination of the concentrations of $n$-pentane and 2-methylbutane present in an equilibrium mixture of the two, as reported by Montgomery,

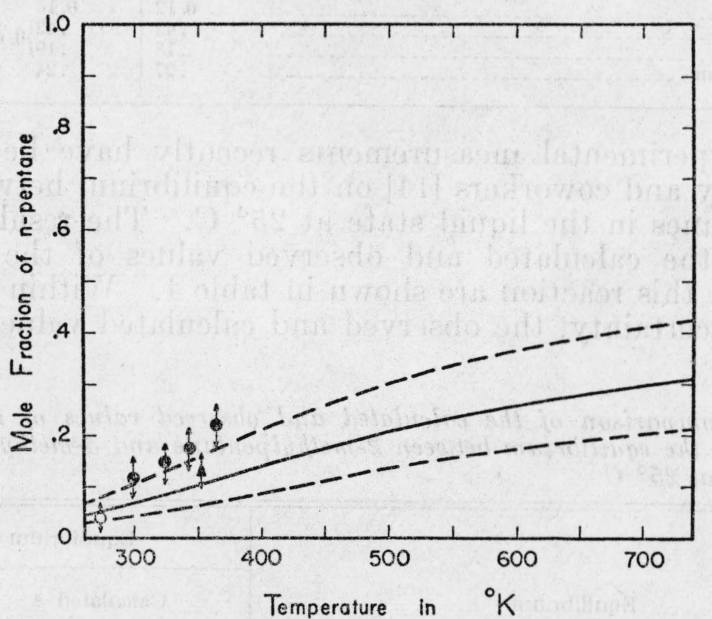

Figure 11.-Comparison of the calculated and observed values of the concentrations for the equilibrium, $n$-pentane (gas) $=2$-methylbutane (gas).

The scale of ordinates gives the mole fraction on $n$-pentane (gas) at equilibrium with 2-methylbutane (gas in a mixture of the two. The scale of abscissas gives the temperature in degrees Kelvin. The solid line represents values derived from those in table 1 , and the broken lines represent the estimated limits of uncertainty. The points, with vertical arrows indicating the estimated uncertainty, represent observed values from the following investigations:

O, Montgomery, McAteer, and Franke [6]; Moldavskii and Nizovkina [15]; $\mathbf{A}$, Schuit, Hoog, and Verheus [13]. 
McAteer, and Franke [6], Schuit, Hoog, and Verheus [13], and Moldavskii and Mzovkina [15], with the values for the same quantities as derived from table 1. The direct observations were made on the liquid phase and have been appropriately corrected to the gas phase. The solid line, the broken lines, and the vertical arrows have the same significance as those in figure 9. Within their respective limits of uncertainty, the directly measured values of the equilibrium concentrations are in accord with the values derived from table 1.

Some data have been reported by Schuit, Hoog, and Verheus [13] on the equilibrium concentrations of four of the five isomers of hexane in the liquid state at $80^{\circ} \mathrm{C}$. From the values given in table 1 and plotted in figure 3 , the equilibrium concentrations for the gaseous state at $80^{\circ} \mathrm{C}$ may be calculated. These values may be converted to the liquid state, utilizing values of the ratios of the vapor pressures of the pure components at this temperature and assuming that the partial pressure of a given component in the liquid mixture is equal to its mole fraction times its vapor pressure in the pure state. The results of a comparison of the calculated and observed concentrations are shown in table 3 . Within the respective limits of uncertainty, the observed and calculated values are in accord.

TABLE 3.-Comparison of the calculated and observed concentrations for the equilibrium involving n-hexane, 2-methylpentane, 3-methylpentane, and 2,3-dimethylbutane, in the liquid state at $80^{\circ} \mathrm{C}$

\begin{tabular}{|c|c|c|c|}
\hline 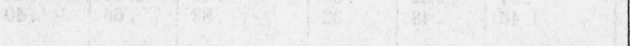 & \multicolumn{3}{|c|}{ Mole fraction } \\
\hline \multirow[t]{2}{*}{ Isomer } & \multicolumn{2}{|c|}{ Calculated } & \multirow{2}{*}{$\frac{\text { Observed [13] }}{\text { Liquid }}$} \\
\hline & Gas & Liquid & \\
\hline $\begin{array}{l}n \text {-Hexane } \\
\text { 2-Methylpentane } \\
\text { 3-Methylpentane } \\
\text { 2,3-Dimethylbutane }\end{array}$ & $\begin{array}{r}0.12 \\
.43 \\
.18 \\
.27\end{array}$ & $\left.\begin{array}{l}0.15 \\
.42 \\
.19 \\
.24\end{array}\right\} 0.61$ & $\begin{array}{r}0.13 \pm 0.10 \\
.70 \pm 0.10 \\
.18 \pm 0.08\end{array}$ \\
\hline
\end{tabular}

Direct experimental measurements recently have been made by Montgomery and coworkers [14] on the equilibrium between the two methylpentanes in the liquid state at $25^{\circ} \mathrm{C}$. The results of a comparison of the calculated and observed values of the equilibrium constant for this reaction are shown in table 4. Within the assigned limits of uncertainty, the observed and calculated values are well in accord.

TABLE 4.-Comparison of the calculated and observed values of the equilitrium constant for the equilibrium between $2-m e t h y l p e n t a n e$ and 3-methylpentane in the liquid state at $25^{\circ} \mathrm{C}$

\begin{tabular}{|c|c|c|c|}
\hline & \multicolumn{3}{|c|}{ Equilibrium constant } \\
\hline \multirow[t]{2}{*}{ Equilibrium } & \multicolumn{2}{|c|}{ Calculated a } & \multirow{2}{*}{$\frac{\text { Observed [14] }}{\text { Liquid }}$} \\
\hline & Gas & Liquid & \\
\hline 3-Methylpentan $\theta=2$-methylpentan $\theta$ & $\begin{array}{c}(4.71) \\
2.84 \\
(1.72)\end{array}$ & $\begin{array}{c}(4.29) \\
2.59 \\
(1.57)\end{array}$ & $1.96 \pm 0.70$ \\
\hline
\end{tabular}

\footnotetext{
a The values in parentheses above and below the calculated values indicate, respectively, the estimated
} upper and lower limits of uncertainty. 


\section{CONCLUSION}

On the basis of the present data, the following general conclusions may be made with regard to the butanes, pentanes, hexanes, and heptanes, in the gaseous state:

(a) At $25^{\circ} \mathrm{C}$, the normal isomer is thermodynamically the least stable in each case, with the exception that 3-ethylpentane is less stable than $n$-heptane. Relative to the other isomers, the normal isomer increases in stability with increase in temperature, and at $1,000^{\circ} \mathrm{K}$ is among the most stable of the isomers.

(b) At $25^{\circ} \mathrm{C}$, the 2,2-dimethyl isomer is in each case the most stable, but it rapidly becomes less stable with increasing temperature and at $1,000^{\circ} \mathrm{K}$ is among the least stable of the isomers.

\section{REFERENCES}

[1] J. G. Aston, R. M. Kennedy, and S. C. Schumann, J. Am. Chem. Soc. 62, $2059(1940)$.

[2] J. G. Aston and G. H. Messerly, J. Am. Chem. Soc. 62, 1917 (1940).

[3] M. DeSimo, F. McMillan and H. Cheney, unpublished measurements at the Shell Development Company, Emeryville, Calif., reported in reference [13].

[4] G. N. Lewis and M. Randall, Thermodynamics and the Free Energy of Chemical Substances (McGraw-Hill Book Co., New York, N. Y., 1923).

[5] B. L. Moldavskii and T. V. Nizovkina, J. Gen. Chem. (U. S. S. R.) 9, 1652 (1939).

[6] C. W. Montgomery, J. H. McAteer, and N. W. Franke, J. Am. Chem. Soc. 59, 1768 (1937); also paper presented before the Division ot Petroleum Chemistry of the American Chemical Society at the meeting in Baltimore, April 3 to $7,1939$.

[7] C. W. Montgomery, J. H. McAteer, and W. A. Horne, Gulf Research \& Development Co., Pittsburgh, Pa., private communication to the authors.

[8] K. S. Pitzer, Chem Rev. 2\%, 39 (1940); J. Chem. Phys. 8, 711 (1940).

[9] E. J. R. Prosen and F. D. Rossini, J. Research NBS 2\%, 519 (1941) RP1439.

[10] F. D. Rossini, Chem Rev. 2\%, 1 (1940).

[11] F. D. Rossini and E. J. R. Prosen, J. Am. Chem. Soc. 62, 2250 (1940).

[12] F. D. Rossini and W. E. Deming, J. Wash. Acad. Sci. 29, 416 (1939).

[13] G. C. A. Schuit, H. Hoog, and J. Verheus, Rec. trav. chim. Pays-bas 59, 793 (1940).

[14] C. W. Montgomery, Gulf Research \& Development Co., Pittsburgh, Pa., private communication.

[15] B. L. Moldavskii and T. V. Nizovkina, J. Gen. Chem. (U. S. S. R.) 10, 1183 (1940).

Washington, October 17, 1941. 